\title{
Medicinal Plants and Natural Products as Potential Sources for Antiparkinson Drugs*
}

Authors

Affiliation
José-Luis Ríos, María Onteniente, Dolores Picazo, María-Carmen Montesinos

Departament de Farmacologia, Facultat de Farmàcia, Universitat de València, Burjassot (Valencia), Spain

\author{
Key words \\ - Parkinson disease \\ - caffeine \\ medicinal plants \\ - natural products \\ - neuroprotection
}

\section{Abstract}

Parkinson's disease is a progressive neurodegenerative dysfunction characterized by the loss of pigmented dopaminergic neurons of the nigrostriatal system with a consequent dopamine decrease. The reduction of dopamine levels produces neuronal damage, depigmentation of the substantia nigra, and the presence of intracellular inclusions in dopaminergic neurons. Treatments for Parkinson's disease aim for improving these motor symptoms by increasing the dopaminergic signal in the striatum with levodopa in combination with enzyme inhibitors or anticholinergic drugs. Nevertheless, natural products can act as neuroprotective agents by reducing the progression of the disease and the inflammatory process. In the present review, we have compiled data on the principal medicinal plants and natural prod- ucts as potential antiparkinsonian agents. They act by different mechanisms, such as the inhibition of $\alpha$-synuclein condensation, reduction of oxidative stress and neuro-inflammation, increase of dopaminergic neurons survival, or the blockade of the $A_{2}$ receptor.

\section{Abbreviations}

$\nabla$

AADC: aromatic L-amino acid decarboxylase

CNS: central nervous system

COMT: catechol-O-methyltransferase

MAO-B: monoamine oxidase-B

$\mathrm{MPP}^{+}$: 1-methyl-4-phenylpyridinium

MPTP: 1-methyl-4-phenyl-1,2,3,6-tetra-

hydropyridine

ROS: $\quad$ reactive oxygen species received February 25, 2016

revised April 5, 2016

accepted April 10, 2016

Bibliography

DOI http://dx.doi.org/

10.1055/s-0042-107081

Published online May 25, 2016

Planta Med 2016; 82: 942-951

(c) Georg Thieme Verlag KG

Stuttgart · New York .

ISSN 0032-0943

\section{Correspondence}

Prof. José-Luis Rios

Departament de Farmacologia

Facultat de Farmàcia

Universitat de València

Av. Vicent Andres Estelles s/n

46100 Burjassot

Valencia

Spain

Phone: + 34963544973

Fax: + 34963544943

riosjl@uv.es

\section{Introduction}

\section{$\nabla$}

Parkinson's disease belongs to a group of sicknesses included in the so-called movement disorders [1]. It is a progressive neurodegenerative dysfunction associated with age and affects mainly movement. This disease is characterized by the loss of pigmented dopaminergic neurons of the nigrostriatal system with a consequent dopamine decrease. In turn, the reduction of dopamine levels in the caudate and putamen of the basal ganglia leads to the appearance of a number of pathological manifestations, such as neuronal damage, depigmentation of the substantia nigra, and the presence of intracellular inclusions in the dopaminergic neurons called Lewy bodies [2]. The diagnosis is based on clinical symptoms, such

\footnotetext{
* Dedicated to Professor Dr. Dr. h.c. mult. Kurt Hostettmann in recognition of his outstanding contribution to natural product research.
}

as the presence of a hypokinetic rigid syndrome characterized by the four cardinal motor signs: bradykinesia, stiff muscles, resting tremor, and impaired postural reflexes with locomotion difficulty $[3,4]$.

After Alzheimer's disease, Parkinson's has the second highest prevalence within degenerative diseases of the nervous system. This disease affects about 4500000 people worldwide and, in 2030 , the number of affected may double $[5,6]$. Several studies suggest that Parkinson's disease in older ages is etiologically related to environmental factors, while in the cases of young people, there is a genetic component. In addition, it has been observed that the disease affects about $50 \%$ more men than women $[1,6-8]$.

From a physiopathological point of view, the loss of dopaminergic input pulses to the striatum produces an imbalance between the dopaminergic pathway from the mesencephalon and the glutamatergic pathway from cortical, thalamic, and 


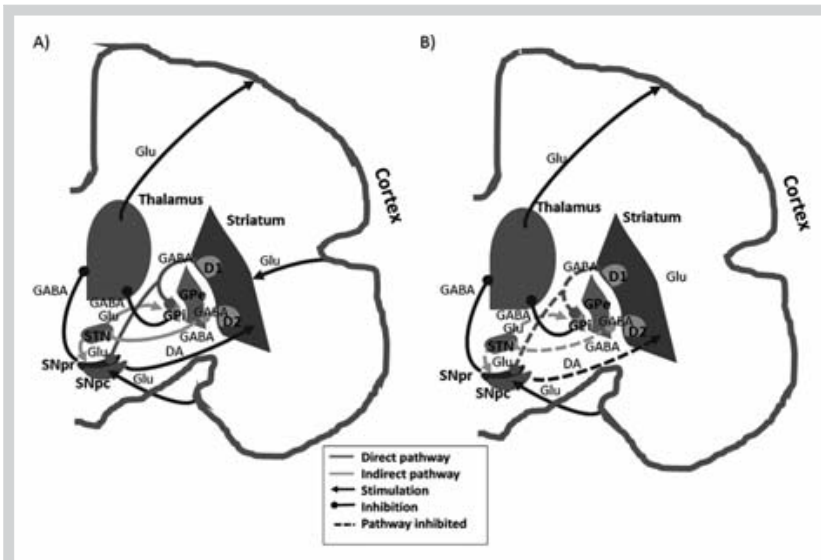

Fig. 1 Differences between healthy people (A) and people with Parkinson's disease (B). GABA: gamma-aminobutyric acid; Glu: glutamate; DA: dopamine; D1: D1 dopamine receptor; D2: D2 dopamine receptor; SNT: subthalamic nucleus; SNpr: substantia nigra pars reticulate; SNpc: substantia nigra pars compacta; GPe: external segment of the globus pallidus; GPi: internal segment of the globus pallidus.

limbic areas. These effects are due to the lack of inhibition of dopaminergic receptor $D_{2}$, which decreases the excitatory input stimuli to the cortex, resulting in the typical motor problems of the disease [9]. Current therapies for Parkinson's pursue improving these motor symptoms, and they are designed, therefore, to increase the dopaminergic signal in the striatum ( Fig. 1). Thus, the pharmacological treatment of Parkinson's disease usually uses direct or indirect potentiation of dopaminergic activity or administration of anticholinergic drugs [10]. The main therapeutic strategies are summarized in 8 Table 1 [11].

In addition to the standard treatments, there are other different perspectives and measures intended to reduce the progression of the disease, such as the use of agents for neuroprotection [2, 10,12]. Moreover, epidemiological studies have demonstrated that inflammation might be involved in the etiology of sporadic Parkinson's predisposition, because the incidence of the disease is lower in patients that consume nonsteroidal anti-inflammatory drugs [2].

In the present review, we have compiled data on the principal medicinal plants and natural products with neuroprotective properties, with a special emphasis on Parkinson's disease.

\section{Methods for the Study of Medicinal Plants in Parkinson's \\ $\nabla$}

In the research of the pharmacology of medicinal plants and natural products against Parkinson's disease, most studies are aimed against potential targets, which could provide neuroprotection, blunt brain inflammation, or neutralize mediators implicated in the pathogenesis of Parkinson's disease. In the first case, there are compounds with antioxidant properties with specific effects in neuronal tissue; in the second, there are studies on antiinflammatory agents with effects on the brain; and in the third group, there are compounds with specific effects on the dopaminergic system, either with agonist properties or those that reduce or avoid dopamine metabolism. In addition, a fourth group consists of compounds with antagonism on muscarinic or ionotropic glutamate receptors in the CNS. Finally, a fifth group
Table 1 Pharmacological strategies in the treatment of Parkinson's disease [11]; MAO-B, COMT and AADC, CNS.

\begin{tabular}{|c|c|}
\hline Increase dopaminergic activity & Drug \\
\hline $\begin{array}{l}\text { Increase the endogenous production } \\
\text { of dopamine }\end{array}$ & Levodopa \\
\hline Mimic the effects of dopamine with agonists & Pramipexole, pergolide \\
\hline Prevent degradation of endogenous dopamine & Inhibitors of MAO-B \\
\hline Prevent degradation of exogenous dopamine & $\begin{array}{l}\text { Inhibitors of COMT } \\
\text { and AADC }\end{array}$ \\
\hline Non-dopaminergic effects & Drug \\
\hline Blockade of muscarinic receptors in CNS & Trihexyphenidyl \\
\hline Blockade of ionotropic glutamate in CNS & Amantadine \\
\hline
\end{tabular}

includes compounds that antagonize adenosine receptors, because today the relationship between the adenosine system and Parkinson's disease is known. All these mechanisms could be valid therapeutic alternatives for the prevention or treatment of Parkinson's disease.

\section{Oxidative stress, antioxidant activity, and neuroprotection}

The mechanisms involved in the pathogenesis and progression of Parkinson's disease are not fully understood, but there are clear evidences on the role of oxidative stress in the degeneration of dopaminergic neurons. The maintenance of the redox potential is an important factor for neuronal survival, and for that, its disruption might interfere with other biological processes in the cells, leading to cell death. Oxidative stress damages cellular proteins and disrupts lipid membranes, which in turn produce more ROS in the brain, mitochondrial dysfunction, and neuro-inflammation. Therefore, the protective mechanisms implicated in the regulation of these processes should be considered a research focus for Parkinson's disease treatment. However, the failures of experiments with antioxidant compounds and strategies tested to date should guide future newer approaches in this kind of research [13]. In fact, in Parkinson's disease, dopaminergic cell death clearly correlates with mitochondrial complex I impairment, oxidative stress, microglial activation, and the formation of Lewy bodies. There is also a relationship between the consumption of berries rich in anthocyanins and proanthocyanidins and a reduction in Parkinson's disease risk. For this reason, many medicinal plants and their principles could be beneficial for maintaining nerve cell function and for treating neurodegenerative disorders by reducing oxidative stress. The regulation of redox signaling and the inhibition of the increased ROS production would contribute to increase the longevity and decelerate the progression of dopaminergic cell death seen in patients with Parkinson's disease. In this context, Koppula et al. [14] reviewed the principal knowledge concerning medicinal plants on the regulation of the redox status and ROS inhibition in experimental models of Parkinson's. Some of them are: Bacopa monnieri (L.) Pennell (Scrophulariaceae), Cassia obtusifolia L. (Caesalpiniaceae), Chrysanthemum indicum L. (Asteraceae), Croton celtidifolius Baill (Euphorbiaceae), Gastrodia elata Blume (Orchidaceae), Ginkgo biloba L. (Ginkgoaceae), Gynostemma pentaphyllum (Thunb.) Makino (Cucurbitaceae), Hibiscus asper Hook.f. (Malvaceae), Hyoscyamus niger L. (Solanaceae), Melissa officinalis L. (Lamiaceae), Morus alba L. (Moraceae), Panax ginseng C. A. Meyer (Araliaceae), Paullinia cupana Mart. var. sorbilis (Sapindaceae), Polygala tenuifolia Willd. (Polygalaceae), and Thuja orientalis L. (Cupressaceae). Of them, $P$. ginseng $[15,16]$ and $B$. monnieri [17-19] have been 
widely reviewed and proposed as future potential antiparkinsonian agents.

\section{Studies on Parkinson murine models}

As commented above, in Parkinson's disease there is a progressive and selective destruction of dopaminergic neurons in the substantia nigra brain region. There are different causes including neurotoxins; therefore, some of them are used as models of Parkinson's disease in animals, such as the compound MPTP, which induces dopaminergic toxicity. MPTP is converted into $\mathrm{MPP}^{+}$in glial cells by MAO-B, and this active metabolite enters into the dopaminergic neurons and binds to complex I and impairs mitochondrial function, producing an overproduction of free radicals, which is responsible for the oxidative stress and the activation of the cell death pathways [20]. Using this experimental model, Yadav et al. [21] studied the potential neuroprotective effect of the anti-inflammatory Ayurveda drug Mucuna pruriens (L.) DC. (Fabaceae). The ethanolic extract of the seeds produced neuroprotection on the MPTP-induced Parkinsonian mouse protocol, showed antioxidant activity against free radicals generated in this model, and improved motor behavior of Parkinsonian mice. The plant extract increased the level of catecholamines and stimulated antioxidant potential in the nigrostriatal region, improved the expression of tyrosine hydrolase in the substantia nigra and striatal regions, and recovered normal expression levels of inducible nitric oxide synthase and glial fibrillary acidic protein in the MPTP-treated animals. The results demonstrate that $M$. pruriens can be effective in the MPTP-induced parkinsonian mouse model. There are no data from this study indicating that it is effective in Parkinson's disease [21].

Of higher interest is the review of Li et al. [22] in which they compiled the principal herbal medicines used to treat Parkinson's disease based on traditional Chinese medicine or modern pharmacological theories. A total of 38 herbal medicines and 11 herbal formulations were tested on different in vitro and in vivo experimental models. They focused their interest on the plant species belonging to 24 genera and 18 families, with the species of genera Acanthopanax, Alpinia, and Astragalus being of the highest interest. The activity was established using rotenone as a direct inhibitor of complex I, and C57/BL6 mice, Wistar rats, C12 cells, and SH-SY5Y cells as tools for the assessment of efficacy and side effects of symptomatic treatments of Parkinson's disease. However, they proposed more in-depth studies to establish their active components and evaluate their efficacy in these experimental models. In the case of Tavakkoli et al. [23], they screened the potential neuroprotective properties of 20 plant extracts and tested them for their potential as inhibitors of oxidative stressinduced neuronal cell damage in a well-established cell model of neurodegeneration (induction of cytotoxicity in PC12 cells by hydrogen peroxide). Among the tested extracts, those of Carthamus oxyacantha Bieb. (Asteraceae), Salvia sclarea L. (Lamiaceae), and Stachys pilifera Benth. (Lamiaceae) showed the best results, and the authors proposed them for further investigation for the discovery of new plant-derived compounds with potential effects on Parkinson's disease.

In different traditional medicines from Asian countries such as India, China, Japan, and Korea, several medicinal plants have been used to treat Parkinson's disease. Their use is built on the experience-based theories in their ancient medical systems. In order to demonstrate the efficacy of these medicinal plants, Song et al. [24] analyzed the antiparkinsonian activities of herbal preparations on in vitro and in vivo neurotoxic models of Parkinson's dis- ease. Fifty-one herbal medicines were analyzed, but they also included, in this study, several chemicals present in the plants. The results were not relevant for plants and their extracts, but several chemical groups were marked as a potential group of active compounds for future studies, such as stilbenoids, flavonoids, catechols, and terpenes, and isolated compounds such as baicalein, puerarin, resveratrol, curcumin, and ginsenosides, which could be candidates for clinical trials. A similar study was carried out to discover new natural products with great potential as therapeutics with neuroprotective activity in Parkinson's disease. They obtained similar results, and cited some potential active compounds: terpenes such as tenuigenin, ginsenoside $\mathrm{Rg} 1$, and astragaloside IV, coumarins such as umbelliferone and esculetin, phenol derivatives such as resveratrol, curcumin, protocatechuic acid, echinacoside, and acteoside, and flavones such as puerarin, luteolin, baicalein, and morin [25]. In the case of flavonoids, it has been established that the regular consumption of these compounds was associated with a reduced risk of neurodegenerative diseases. These properties were not only due to their antioxidant effects, but also exhibit neuroprotective properties through the interaction with cellular signaling pathways followed by transcription and translation that mediate cell function under both normal and pathologic conditions [26].

\section{Other experimental models for studying new agents against Parkinson's disease}

Different experimental models in vivo and in vitro have been introduced for the study of agents to treat Parkinson's disease. Among them, the experimental protocols with a focus on neurodegeneration and neuroprotection are the most widely used. Some examples are the 6-hydroxydopamine-induced neurotoxicity in PC12 cells, rotenone as an inhibitor of mitochondrial respiratory chain complex I in the human neuroblastoma (SHSY5Y) [27], or in the fruit fly (Drosophila melanogaster) [20], and $\mathrm{MPP}^{+}$induced neurotoxicity in zebrafish or PC12 cells [28].

D. melanogaster was introduced as a model for the study of several neurodegenerative diseases, including Parkinson's disease. After several days of treatment with sublethal chronic doses of rotenone, the flies showed characteristic locomotor impairments, which were due to a dramatic and selective loss of dopaminergic neurons in all of the brain clusters [29]. Rotenone is an inhibitor of mitochondrial respiratory chain complex I, which reproduces many features of this disease. Using this dopaminergic cell death elicited by a rotenone test, Strathearn et al. [30] observed that extracts from blueberries (Vaccinium corymbosum L., Ericaceae), grape seed (Vitis vinifera L., Vitaceae), hibiscus (Hibiscus sabdariffa L., Malvaceae), blackcurrant (Ribes nigrum L., Grossulariaceae), and Chinese mulberry (Morus alba L., Moraceae) reduced cell death. Extensively, they demonstrated that extracts rich in anthocyanins and proanthocyanidins showed greater neuroprotection than extracts rich in other polyphenols. In this same model, Sudati et al. [31] investigated the protective effects of Valeriana officinalis L. (Valerianaceae) against the toxicity induced by rotenone in $D$. melanogaster. They observed that valeriana's extract reduced the increase in mRNA expression of the antioxidant enzymes superoxide dismutase and catalase, induced by rotenone in the fruit fly, but no active substances were described.

Jansen et al. [32] studied five Ayurvedic herbs on locomotor behavior also using $D$. melanogaster and rotenone as an experimental model of Parkinson's disease. The studied species were $\mathrm{Mucu}$ na pruriens (L.) DC. (Leguminosae), Withania somnifera (L.) Dunal 
(Solanaceae), Centella asiatica (L.) Urb. (Apiaceae), Sida cordifolia Griseb. (Malvaceae), and Bacopa monnieri. Particularly, this last species significantly improved the climbing ability in this experimental model, and combined with its potentiality for improving cognition and preventing further cognitive declining, makes this species a promising alternative or complementary treatment.

Other species have been proposed as potential agents against Parkinson's disease, but no positive effects have been demonstrated in many cases. For example, Kanazawa and Sakakibara [33] and Pereira and Maraschin [34] proposed the use of a banana (Musa spp.) peel biomass as a raw material source of the biogenic amine dopamine for the development of a pharmaceutical formulation for the treatment of Parkinson's disease. However, no clear conclusions were obtained in this study about the real interest of this species as a source of a medicinal agent against Parkinson's disease. In other cases, the authors reviewed the medicinal plants used in different parts of the world, such as the review on Ayurvedic and Traditional Tibetan Medicine carried out by de Rus et al. [35], in which they selected a series of medicinal plant species to treat Parkinson's disease-related symptoms and other CNS disorders, but no clear conclusion on efficacy or active principles was included.

As mentioned above, Parkinson's disease is characterized by the presence of Lewy bodies and Lewy neurites, which are protein aggregates composed predominantly of the presynaptic protein $\alpha$-synuclein [36]. Although the role of $\alpha$-synuclein in the pathogenesis of Parkinson's disease is not completely understood, the stabilization of nontoxic aggregates could represent a potential therapeutic route [37], and the study on the anti-aggregative properties of natural products has been used as a strategy for the screening of potential protective agents against Parkinson's disease [38]. In the case of the tea polyphenols (epigallocatechin-3-gallate and theaflavins; $\odot$ Fig. 2), they inhibited wild-type $\alpha$-synuclein filament assembly and also disaggregated preformed fibrils. In the case of epigallocatechin-3-gallate ( $\bullet$ Fig. 2 ), it inhibited fibril formation of $\alpha$-synuclein and transformed large $\alpha$ synuclein fibrils into smaller nontoxic, amorphous protein aggregates, which can be considered as a protective effect in the case of Parkinson's disease [36].

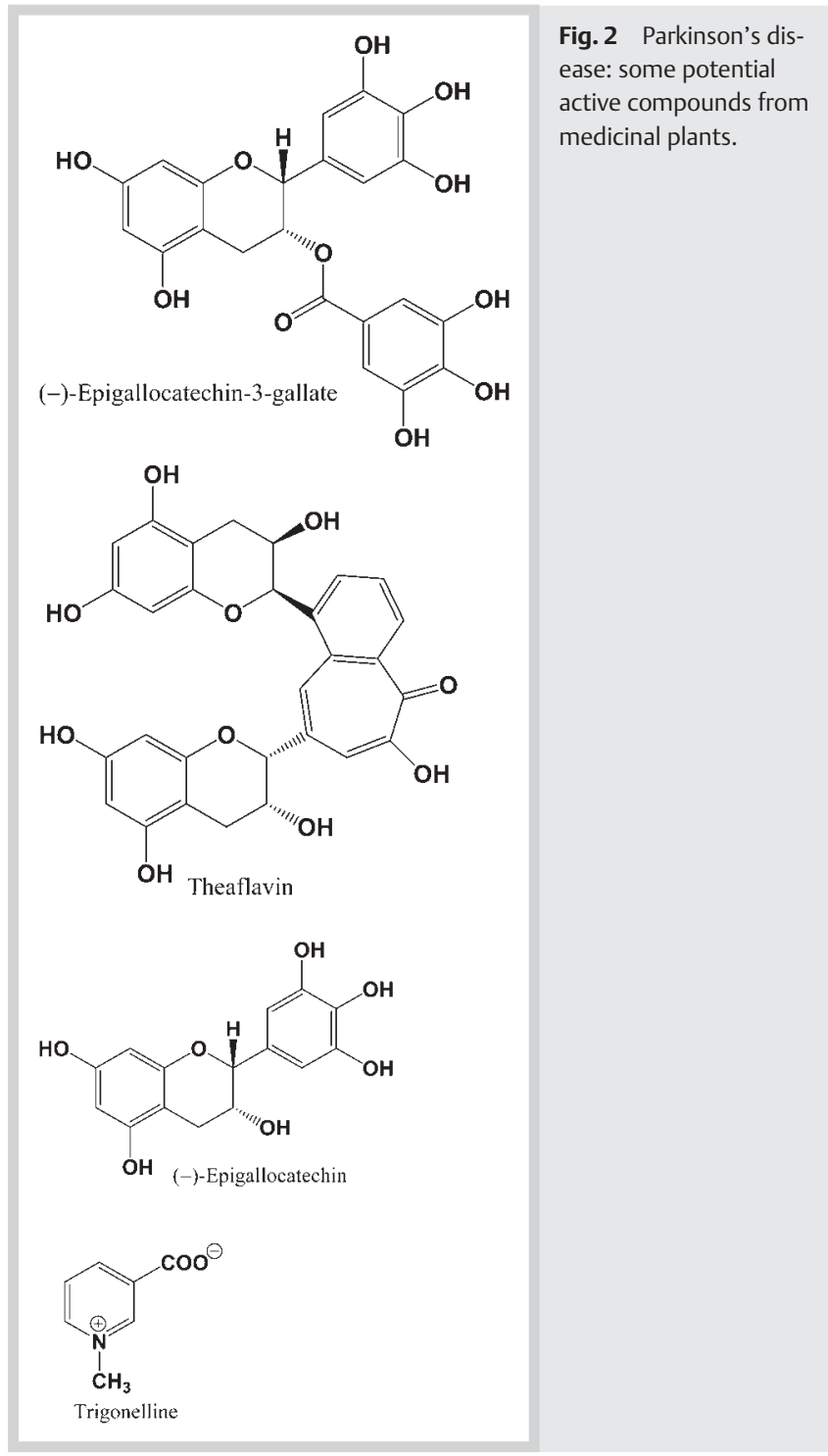

Table 2 Medicinal plants studied as potential antiparkinsonian drugs. Chungsimyeolda-tang is a traditional Korean herbal formula with Polygala tenuifolia Willd. (Polygalaceae), Angelica tenuissima Nakai (Apiaceae), and Dimocarpus longan Lour. (Sapindaceae) (1:1:1,w:w:w) as the major ingredients.

\begin{tabular}{|c|c|c|}
\hline Plants & Experimental model & References \\
\hline Acanthopanax senticosus Harms (Araliaceae) & Stabilization of nontoxic aggregates of $\alpha$-synuclein & [39] \\
\hline Albizia adianthifolia W.Wight (Leguminosae) & 6-Hydroxydopamine rodent model of Parkinson’s disease & [40] \\
\hline Centella asiatica (L.) Urb. (Apiaceae) & Inhibited aggregates' formation, favored fibrils' disintegration & [41] \\
\hline Chungsimyeolda-tang & MPTP-induced neuronal cell death mouse model & [42] \\
\hline Chungsimyeolda-tang & $\mathrm{MPP}^{+}$and rotenone cytotoxicity in nerve growth factor & [43] \\
\hline Crocus sativus L. (Iridaceae) & MPTP mouse model & [44] \\
\hline Decalepis hamiltonii Wight \& Arn. (Asclepiadaceae) & Toxicity in transgenic Drosophila model & [45] \\
\hline Eucommia ulmoides Oliv. (Eucommiaceae) & MPTP and MPP toxicity in vitro & [46] \\
\hline Eucommia ulmoides Oliv. (Eucommiaceae) & 6-Hydroxydopamine-induced death in SH-SY5Y cells & [47] \\
\hline Gastrodia elata Blume (Orchidaceae) & 6-Hydroxydopamine Parkinson's disease mouse model & [48] \\
\hline Lycium chinense Mill. (Solanaceae) & Rotenone-induced neurotoxicity in PC12 cells & [49] \\
\hline Ocimum sanctum L. (Lamiaceae) & Drosophila climbing assay & [50] \\
\hline Sida cordifolia Forssk. (Malvaceae) & Rotenone induced oxidative stress model & [51] \\
\hline Solanum lycopersicum L. (Solanaceae) & Neurotoxicity induced by rotenone in mice & [52] \\
\hline Tinospora cordifolia (Willd.) Miers ex Hook.f. \& Thomson (Menispermaceae) & 6-Hydroxy dopamine induced Parkinsonism & [53] \\
\hline Withania somnifera (L.) Dunal (Solanaceae) & MPTP rat model & [54] \\
\hline
\end{tabular}


Other medicinal plants used in traditional medicines with potential antiparkinsonian activity that have been studied are compiled in $\odot$ Table 2.

\section{Studies on humans: clinical trials}

In some cases, clinical trials with medicinal plants as antiparkinsonian agents have been developed. Several human studies have been carried out to demonstrate the neuroprotective effects of medicinal plants, but usually the improvement of cognitive function was the only outcome being investigated, such as Brahmi (Bacopa monnieri). Several authors have studied this species, which is now considered an interesting drug for future studies in the treatment of Parkinson's disease [17-19]. Nathan et al. [55] carried out a more specific study, consisting of a doubleblind clinical trial with 50 patients with Parkinson's disease being treated with levodopa. They also received a standardized extract of fenugreek (Trigonella foenum-graecum L., Fabaceae) during 6 months (300 mg twice daily). The evaluation of the results showed that the treated patients tolerated the extracts, without impairing the effectiveness of levodopa and causing a reduction in the Unified Parkinson's Disease Rating Scale (UPDRS), which is a rating scale used to follow the longitudinal course of Parkinson's disease. These results suggest that a standardized extract of fenugreek seeds could be an adjuvant to levodopa in the therapy of Parkinson's disease; however, it should be evaluated in a larger population to fully validate its potential benefit in the management of the disease. The authors hypothesize a relevant role of the compound trigonelline in this effect ( $\bullet$ Fig. 2 ).

A double-blind, randomized, placebo-control, delayed clinical study with 410 untreated people with early Parkinson's disease was evaluated for the safety, tolerability, and efficacy of green tea polyphenols. The results demonstrated that green tea polyphenols are well tolerated and provide a mild symptomatic relief in early, untreated patients. However, the active compounds were not identified [36].

\section{Isolated natural products as}

potential antiparkinson agents

Using another experimental model with rotenone-treated human dopaminergic SH-SY5Y cells, Ryu et al. [56] identified amurensin G ( Fig. 3) from a wild grape (Vitis amurensis Rupr., Vitaceae). This compound inhibited the apoptosis induced with rotenone as well as interfered with rotenone-induced $\mathrm{G}_{2} / \mathrm{M}$ cell cycle arrest, while knockdown of beclin1, a regulator of autophagy, abolished the effect of amurensin G. These data collectively indicate that amurensin $G$ attenuates cellular toxicities through the induction of autophagy, because inducers of autophagy attenuate cellular toxicities in Parkinson's disease models. In a screening for antiparkinsonian drugs, Fujimaki et al. [57] observed that two herbal medicines, choi-joki-to and daio-kanzoto, containing Glycyrrhiza sp. showed a neuroprotective effect, and from this species they isolated licopyranocoumarin and glycyrurol ( Fig. 3) as potential neuroprotective agents. Both compounds exert neuroprotection by inhibiting $\mathrm{MPP}^{+}$-induced ROS production and thus limiting c-Jun $\mathrm{N}$-terminal kinase activation, and causing cell death. Because ROS cause oxidative damage to proteins, lipids, and DNA, they are relevant factors implicated in neurodegeneration. The effects of natural products on ROS and the oxidative damage should be ratified in preclinical tests, using the MPTP animal model, but also in clinical studies in order to demonstrate their effectiveness in reducing oxidative stress in the pathogenesis of Parkinson's disease.

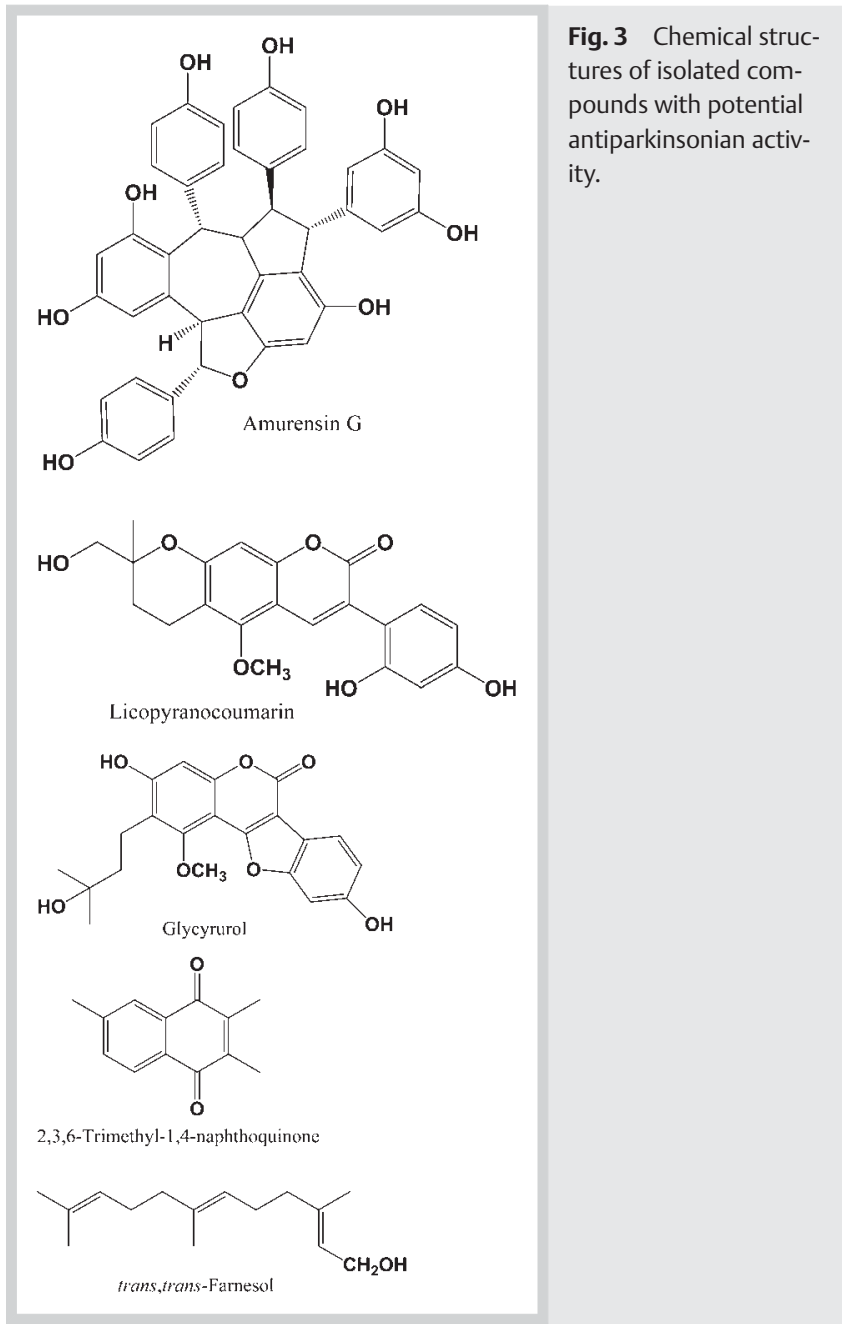

An interesting case is tobacco (Nicotiana tabacum L., Solanaceae). Indeed, epidemiological studies indicate that tobacco smokers showed about a 50\% reduction of incidence of Parkinson's disease vs. nonsmokers [58]. Supposedly, nicotine exerts neuroprotection through specific nicotinic cholinergic receptors. Despite nicotine being considered the agent responsible for the beneficial behavioral and neurological effects of tobacco, levels of other alkaloids present in tobacco, such as cotinine, are also present in the brain after tobacco consummation. Besides the effect of nicotine and some of its derivatives via cholinergic receptors, they also diminish oxidative stress and neuro-inflammation in the brain and improve synaptic plasticity and neuronal survival of dopaminergic neurons [59]. However, in addition to the alkaloids' effects, other compounds have been described as potential active agents. This is the case of 2,3,6-trimethyl-1,4-naphthoquinone and trans,trans-farnesol ( $\odot$ Fig. 3), which were isolated from tobacco leaves and can be detected in tobacco smoke as well. Both compounds decreased the level of MAO-B, causing the subsequent reduction of dopamine degradation. The effects of these compounds can be in addition to the neuroprotective effect of nicotine, which interacts with the nigrostriatal dopaminergic system. Moreover, the in vivo assays demonstrated an improvement of mood, motor skills, and memory in nicotine-treated rats [58]. 
Table 3 Natural products studied as potential antiparkinsonian drugs.

\begin{tabular}{|c|c|c|}
\hline Isolated compound & Experimental protocol & References \\
\hline Astragaloside IV & MPTP-induced parkinsonism model & {$[60]$} \\
\hline Berberine & MPTP and 6-hydroxydopamine-induced Parkinson's disease in rats & [61] \\
\hline Carnosic acid & 6-Hydroxydopamine-induced neurotoxicity in in vivo and in vitro models of Parkinson's disease & [62] \\
\hline Chrysin & 6-Hydroxydopamine-treated PC12 cells & [63] \\
\hline Epicatechin gallate & Transgenic drosophila model of Parkinson's disease & {$[64,65]$} \\
\hline Hesperidin & 6-Hydroxydopamine model of Parkinson's disease & [66] \\
\hline Madecassoside & MPTP-induced parkinsonism model & [60] \\
\hline Onjisaponin B & Stabilization of nontoxic aggregates of $\alpha$-synuclein in PC- 12 cells & [67] \\
\hline Panaxatriol saponins & MPTP-induced parkinsonism model & [60] \\
\hline Protocatechuic acid & 6-Hydroxydopamine-treated PC12 cells & [66] \\
\hline
\end{tabular}

Other compounds with potential interest in the future of Parkinson's disease treatment have been studied and they are compiled in $\odot$ Table 3.

\section{Methylxanthines in Therapy and Prevention of Neurodegeneration \\ $\nabla$}

The second group of plants with potential effects on Parkinson's disease is the species with caffeine. Caffeine ( $\bullet$ Fig. 4 ) is present in different plants and food sources. For example, tea [Camellia sinensis (L.) Kuntze, Theaceae] contains about 2.5-5.5\%, the seeds of coffee [Coffea arabica L. and C. robusta (L.) Linden, Rubiaceae] 0.9-2.6\%, mate [Ilex paraguariensis (A.) St.-Hil., Aquifoliaceae] 0.3-1.7\%, guaraná (Paullinia cupana Kunth. ex H. B.K., Sapindaceae) $2.9-5.8 \%$, cola [Cola nitida (Vent.) Schott \& Endl., Sterculiaceae] $2.0-2.5 \%$, and in a minor quantity, cacao (Theobroma cacao L., Sterculiaceae) with only $0.2-0.3 \%$. The caffeine intake is variable depending on the source and kind of beverage. For example, a cup of coffee $(150 \mathrm{~mL})$ has about 40 to $180 \mathrm{mg}$, whereas a cup of tea $(150 \mathrm{~mL})$ contains about 24 to $50 \mathrm{mg}$. In the case of cacao, the content is lower, for example, $2-7 \mathrm{mg}$ in a cup of liquid chocolate $(150 \mathrm{~mL})$ or 1 to $36 \mathrm{mg}$ for $28 \mathrm{~g}$ of chocolate [68].

Some epidemiological studies revealed a consistent inverse association between the consumption of drinks with caffeine, such as coffee [69,70], yerba mate [71], or tea [70], and the risk of Parkinson's disease. Because the common active compound in all of them is caffeine, it can be an object of scientific interest for pharmacology purposes. In addition, no significant negative effects on human health were described and it can be considered a safe compound given its extensive and long-time use [72]. Since several mechanisms have been implicated in the effects of the caffeine blockade of adenosine receptors, inhibition of acetylcholinesterase, monoamine oxidase, phosphodiesterases, or the blockade of ryanodine receptors and others, new chemical compounds based on a caffeine moiety have been prepared and introduced in Parkinson's therapy [72]. Some of them are istradefylline and preladenant.

\section{Relationship between adenosine system and Parkinson's disease}

Adenosine ( $\bullet$ Fig. 4 ) is an endogenous nucleoside essential for cells as the base of biological molecules such as nucleotides and nucleic acids, as a part of cofactors required for various enzymatic reactions and energy metabolism, as well as second messengers, and for storage and transmission of genetic information and protein synthesis. In addition, the concentration of adenosine can in-

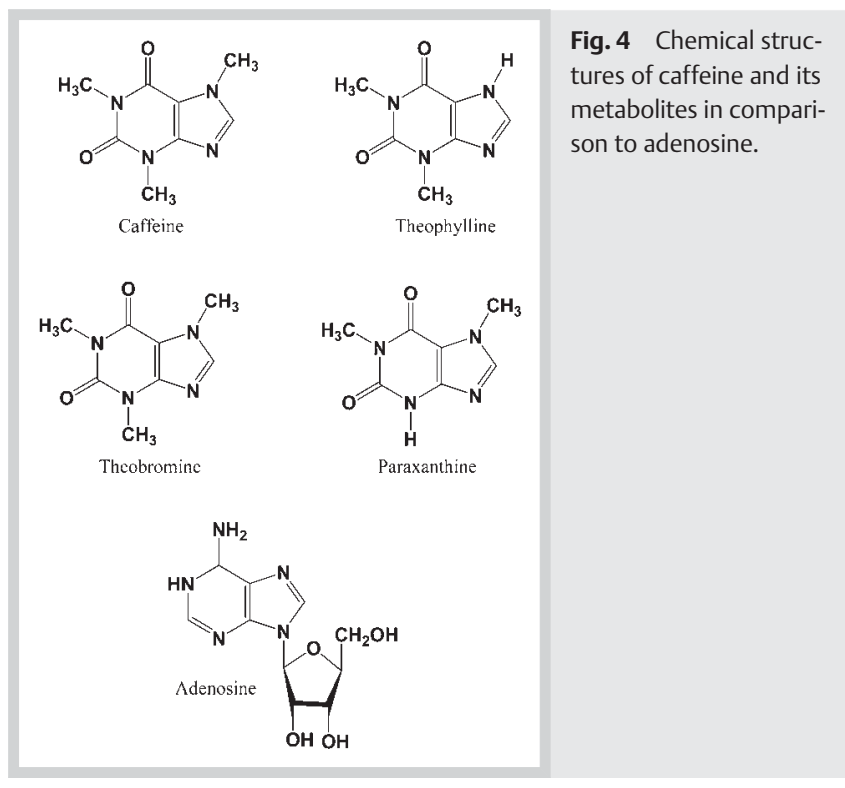

crease both by intracellular production and by formation from extracellular adenine nucleotides released by cells [73-75]. Recent studies have provided relevant information on the implication of adenosine in the pathogenesis and resolution of several neurodegenerative diseases. Indeed, blockade of the $A_{2 A}$ receptor showed a neuroprotective effect, which is the starting point of clinical trials for Parkinson's disease [76]. Caffeine and other methylxanthines act as specific antagonists of these receptors and their potency is proportional to their affinity to the receptor. In addition, the adenosine $A_{2 A}$ and the dopamine $D_{2}$ receptors on the striatopallidal neurons share a location, which serves as a basis for assuming a possible functional interaction between these two receptors [77]. In fact, it is clear that there is an antagonistic relationship between these two receptors in the brain striatum, and after blocking the adenosine $A_{2 A}$ receptor, the effects of the lack of dopamine can be reduced and the motor symptoms characteristic of Parkinson's disease improve.

An overview of studies related to methylxanthines and Parkinson's disease shows that the interest in research in this field arises from an epidemiological study that started in the 1960s of the last century in which a protective association between caffeine consumption and the development of Parkinson's disease was observed. After this study, several molecules with antagonist properties of the adensine $A_{2 A}$ receptor were introduced as an adjunct to conventional therapy, and are now in phase III clinical 
trials. In 1965, a prospective observation known as the Honolulu Heart Program was started. The data collected from 1968 until 1996 showed an inverse relationship between coffee intake and incidence of Parkinson's disease, because people who drank coffee and other caffeinated beverages had a significantly lower incidence than non-drinkers [7]. Indeed, this study, published in 2000, was developed in the Honolulu Heart Program during 30 years with 8004 men (aged 45-68 years) who consumed caffeine from coffee and other sources. During this observational period, 102 men developed Parkinson's disease. These results indicate an incidence of 1.9 per 10000 (men who drank caffeine) vs. 10.4 per 10000 (men who no drank caffeine). It was concluded that an increased intake of caffeine itself implies a significant reduction in the incidence of Parkinson's disease [7].

This initial study was supported by other prospective cohorts made for the same purpose, such as the Health Professionals' Follow-up Study (HPFS) and the Nurses' Health Study (NHS) [78], and a more recent clinical trial conducted by the Finnish Mobile Clinic Health Examination (FMCHE) survey [79]. These studies, performed with more than 146000 men and women during 48 years, arrived at the same conclusion: the existence of an inverse dose-dependent relationship between caffeine consumption and the development of Parkinson's disease. The HPFS and NHS studies included people of both sexes (47351 men and 88565 women). During the period of 10 years for men and 16 years for women, there were 288 incident cases of Parkinson's disease [79]. The protective effects seemed to be higher in man; however, this observation has not been confirmed, because in the FMCHE study with the Finnish population, developed in 2008, with 6710 men and women between 50 and 79 years, it was observed that the incidence was equal between men and women. However, during the 22 years of the survey, 101 people developed Parkinson's, corroborating the inverse association with caffeine [80].

The results mentioned above [78] are relevant, because the effect of estrogen on the neuroprotective capacity of caffeine could justify a relationship between gender, caffeine, estrogen, and risk of disease. This possible relationship was studied through the polymorphisms in caffeine metabolizing genes, such as CYP1A2 and NAT2, and estrogen receptors (ESR1 and ESR2). These results indicated that the beneficial effects of caffeine might be limited to men and postmenopausal women that did not receive hormone replacement therapy [81]. In addition, the possibility that the side effects of a high consumption of coffee can produce the opposite effect on Parkinson's has also been analyzed. However, the authors concluded that other factors, such as body mass index and blood cholesterol levels, but not caffeine, negatively influenced the incidence of Parkinson's [78].

With these premises and knowledge, several studies on neuroprotection in animals treated with caffeine began. The principal interest was to define the role of the $A_{2 A}$ receptor blockade and its potential usefulness in treating Parkinson's disease. In 2000, the team of Jiang-Fan Chen [82], one of the pioneers in this field, conducted a study in which the effects of caffeine were investigated. Male C57BL mice were first subjected to a pretreatment consisting of either caffeine or vehicle and then they were treated with a single intraperitoneal injection of MPTP or vehicle. Mice pretreated with caffeine showed diminished MPTP-induced toxicity. This effect was corroborated by new studies in which a dose-dependence of caffeine was established with a reduction of dopamine loss. This neuroprotective effect resides in the blockade of adenosine $A_{2 A}$ receptors, which can be considered a step forward for future studies with more selective antagonists [8284]. The common point of these studies was that a pretreatment with caffeine significantly attenuates the loss of dopamine without showing a phenomenon of tolerance.

\section{Clinical studies with caffeine}

for preventing neurodegeneration

It is known that only $100 \mathrm{mg}$ of caffeine in plasma in humans is sufficient to block adenosine receptors $[68,85]$. However, other xanthines and caffeine metabolites can also be active. In this sense, Xu et al. [86] studied the potential neuroprotective activity linked to the therapeutic effect of caffeine and the effects of theophylline and paraxanthine, a metabolite of caffeine. Their data showed that the protection afforded by caffeine on dopaminergic cells is maintained in time thanks to its major metabolites. Indeed, in humans, approximately $80 \%$ of caffeine is metabolized to paraxanthine, theobromine, and theophylline ( Fig. 4). Paraxanthine can contribute to the pharmacological action of caffeine in people that consume caffeine during the long term at higher doses because paraxanthine can accumulate in plasma due to its saturable metabolism and therefore contribute to the pharmacological effect of caffeine. Furthermore, paraxanthine and theophylline have similar properties and decrease the loss of striatal dopamine caused by $\mathrm{MPP}^{+}$in mice. In addition, caffeine and its metabolites theophylline and paraxanthine are antagonists of adenosine receptors and phosphodiesterase inhibitors as well as inhibitors of calcium release, although for these last two actions they require higher concentrations [86].

As mentioned above, the epidemiological studies linked the regular consumption of caffeine with a lower risk of developing Parkinson's disease. With this background and based on the hypothesis that caffeine, as an antagonist of adenosine $A_{2 A} R$, improves motor function even when being treated with levodopa, neuroprotective properties were attributed to caffeine due to its local action on the basal ganglia and substantia nigra. In a 6-week randomized controlled trial with 61 patients, Postuma et al. [87] reported that caffeine provided only equivocal borderline improvement in patients with Parkinson's disease who experienced excessive somnolence, but improved objective motor measures. With this same objective, different clinical studies have been developed with the proposal of establishing the optimal dose of caffeine to get the maximum motor benefit with minimal adverse effects in a preliminary phase II [88], and to evaluate the efficacy of caffeine ( $200 \mathrm{mg}$ ) vs. placebo for motor and non-motor aspects of the disease in phase III [89].

\section{Conclusions}

In the absence of an adequate treatment for Parkinson's disease, it is undeniable that there is a need to identify new targets for action. One of those targets, as already mentioned, is the receptor of adenosine $A_{2} \mathrm{~A}$. The molecules that antagonize these receptors have been established as promising agents in the pharmacotherapy of Parkinson's. Moreover, the evidence also suggests that they possess a neuroprotective effect that may prevent the development of dyskinesia and the complications of levodopa therapy [90]. In addition, the benefits of these antagonists are additive to dopamine replacement therapy.

Inhibitors of MAO-B also constitute an established target and are currently part of the standard therapy to get elevated dopamine levels, and they have also been attributed as having promising neuroprotective qualities. The inhibitors of this enzyme are espe- 
cially interesting because there is a direct association between increased activity of these enzymes and age [91].

Some previous studies reported no clear effects of caffeine in patients treated with standard therapies. Two early clinical studies evaluated caffeine as a potential symptomatic agent in Parkinson's disease. However, these studies had the limitation of being small scale with only six patients being treated in each trial, and comparing the modification of the antiparkinsonian efficacy of levodopa or piribedil [92] and bromocriptine [93]. In both cases, there were no changes in the pharmacological response of the drugs. Nevertheless, these discrepancies are of interest and reveal the limitations of the extrapolation of results obtained in studies with animals to human.

Regarding the possible use of medicinal plants and natural products, the search for new compounds is an objective of high interest; however, the general screening of antioxidant activity of plant extracts or isolated compounds is not the best system for obtaining future medicinal agents. In this case, the search for selective compounds on specific targets is a more desirable objective than the general screening, or tests with low selectivity for this purpose. An alternative could be to develop different models in parallel to obtain at least positive effects in two different experimental models of Parkinson's disease. The inhibition of $\alpha$ synuclein aggregates, the toxicity of 6-hydroxydopamine in PC12 cells, and the use of rotenone as a direct inhibitor of complex I in cells and animals can be complementary tests for a more selective screening.

\section{Acknowledgements}

$\nabla$

J.L.R. wants to thank Professor Hostettmann for his support and teachings in different facets of my scientific life. Also, and especially, I want to remember his disciple and friend, Dr. Andrew Marston, also my friend, who gave me his help, advice, and friendship throughout our lives. We miss you and will never forget you.

\section{Conflict of Interest}

The authors declare no conflicts of interest.

\section{References}

1 Office of Communications and Public Liaison, National Institute of Neurological Disorders and Stroke, National Institutes of Health, Bethesda, $M D$, USA. Available at http://www.ninds.nih.gov/disorders/parkinsons_disease/detail_parkinsons_disease.htm. Accessed January 21, 2016

2 Nestler EJ, Hyman SE, Malenka RC. Neurodegeration. In: Sydor A Brown RY editors. Molecular neuropharmacology: a foundation for clinical neuroscience, 2nd edition. New York: McGraw Hill; 2009: 409-442

$3 W u$, Hallett $M$, Chan P. Motor automaticity in Parkinson's disease. Neurobiol Dis 2015; 82: 226-234

4 Nagatsu T, Sawada M. L-dopa therapy for Parkinson's disease: past, present, and future. Parkinsonism Relat Disord 2009; 15: S3-S8

5 The Parkinson Study Group QE3 Investigators. A randomized clinical trial of high-dosage coenzyme Q10 in early Parkinson's disease: No evidence of benefit. JAMA Neurol 2014; 71: 543-552

6 Ross GW, Abbott RD, Petrovitch H, Morens DM, Grandinetti A, Tung KH, Tanner CM, Masaki KH, Blanchette PL, Curb JD, Popper JS, White LR. Association of coffee and caffeine intake with the risk of Parkinson's disease. JAMA 2000; 283: 2674-2679
7 Schapira AHV, Olanow CW, Greenamyre JT, Bezard E. Slowing of neurodegeneration in Parkinson's disease and Huntington's disease: future therapeutic perspectives. Lancet 2014; 384: 545-555

8 Kulisevsky J, Poyurovsky M. Adenosine $\mathrm{A}_{2 \mathrm{~A}}$-receptor antagonism and pathophysiology of Parkinson's disease and drug-induced movement disorders. Eur Neurol 2012; 67: 4-11

9 Standaert $D$. Treatment of central nervous system degenerative disorders. In: Brunton LL, Chabner B, Knollman B, editors. Goodman and Gilman's the pharmacological basis of therapeutics, 12th edition. New York: McGraw-Hill; 2011: 609-668

10 Goldman JG, Weintraub D. Advances in the treatment of cognitive impairment in Parkinson's disease. Mov Disord 2015; 30: 1471-1489

$11 \mathrm{Xu} K$, Bastia E, Schwarzschild M. Therapeutic potential of adenosine $A_{2 A}$ receptor antagonists in Parkinson's disease. Pharmacol Ther 2005; 105: $267-310$

12 ClinicalTrials.gov Investigation of Cogane (PYM50028) in early-stage Parkinson's disease (CONFIDENT-PD). Available at https:// clinicaltrials.gov/ct2/show/NCT01060878. Accessed January 21, 2016

13 Dias V, Junn E, Mouradian MM. The role of oxidative stress in Parkinson's disease. J Parkinsons Dis 2013; 3: 461-491

14 Koppula S, Kumar H, More SV, Lim HW, Hong SM, Choi DK. Recent updates in redox regulation and free radical scavenging effects by herbal products in experimental models of Parkinson's disease. Molecules 2012; 17: 11391-11420

15 Van Kampen JM, Baranowski DB, Shaw CA, Kay DG. Panax ginseng is neuroprotective in a novel progressive model of Parkinson's disease. Exp Gerontol 2014; 50: 95-105

16 González-Burgos E, Fernandez-Moriano C, Gómez-Serranillos MP. Potential neuroprotective activity of ginseng in Parkinson's disease: a review. J Neuroimmune Pharmacol 2015; 10: 14-29

17 Roodenrys S, Booth D, Bulzoma S, Phipps A, Micallef C, Smoker J. Chronic effects of Brahmi (Bacopa monnieri) on human memory. Neuropsychopharmacology 2002; 27: 279-281

18 Stough C, Downey LA, Lloyd J, Silber B, Redman S, Hutchison C, Wesnes K, Nathan PJ. Examining the nootropic effects of a special extract of Bacopa monniera on human cognitive functioning: 90 day doubleblind placebo-controlled randomized trial. Phytother Res 2008; 22: 1629-1634

19 Barbhaiya HC, Desai RP, Saxena VS, Pravina K, Wasim P, Geetharani P, Allan JJ, Venkateshwarlu K, Amit A. Efficacy and tolerability of BacoMind $^{\circledR}$ on memory improvement in elderly participants - a double blind placebo controlled study. Am J Pharmacol Toxicol 2008; 3: 425-434

20 Dauer W, Przedborski S. Parkinson's disease: mechanisms and models Neuron 2003; 39: 889-909

21 Yadav SK, Prakash J, Chouhan S, Westfall S, Verma M, Singh TD, Singh SP. Comparison of the neuroprotective potential of Mucuna pruriens seed extract with estrogen in 1-methyl-4-phenyl-1,2,3,6-tetrahydropyridine (MPTP)-induced PD mice model. Neurochem Int 2014; 65: 1-13

22 Li XZ, Zhang SN, Liu SM, Lu F. Recent advances in herbal medicines treating Parkinson's disease. Fitoterapia 2013; 84: 273-285

23 Tavakkoli M, Miri R, Jassbi AR, Erfani N, Asadollahi M, Ghasemi M, Saso L, Firuzi O. Carthamus, Salvia and Stachys species protect neuronal cells against oxidative stress-induced apoptosis. Pharm Biol 2014; 52: 1550-1557

24 Song JX, Sze SC, Ng TB, Lee CK, Leung GP, Shaw PC, Tong Y, Zhang YB. AntiParkinsonian drug discovery from herbal medicines: what have we got from neurotoxic models? J Ethnopharmacol 2012; 139: 698-711

25 More SV, Kumar H, Kang SM, Song SY, Lee K, Choi DK. Advances in neuroprotective ingredients of medicinal herbs by using cellular and animal models of Parkinson's disease. Evid Based Complement Alternat Med 2013; 2013: 957875

26 Solanki I, Parihar P, Mansuri ML, Parihar MS. Flavonoid-based therapies in the early management of neurodegenerative diseases. Adv Nutr 2015; 6: 64-72

27 De Pedro N, Cantizani J, Ortiz-López FJ, González-Menéndez V, Cautain B, Rodríguez L, Bills GF, Reyes F, Genilloud O, Vicente F. Protective effects of isolecanoric acid on neurodegenerative in vitro models. Neuropharmacology 2015; 101: 538-548

28 Lu XL, Lin YH, Wu Q Su FJ, Ye CH, Shi L, He BX, Huang FW, Pei Z, Yao XL. Paeonolum protects against $\mathrm{MPP}^{+}$-induced neurotoxicity in zebrafish and PC12 cells. BMC Complement Altern Med 2015; 15: 137

29 Coulom H, Birman S. Chronic exposure to rotenone models sporadic Parkinson's disease in Drosophila melanogaster. J Neurosci 2004; 24: 10993-10998 
30 Strathearn KE, Yousef GG, Grace MH, Roy SL, Tambe MA, Ferruzzi MG, Wu QL, Simon JE, Lila MA, Rochet JC. Neuroprotective effects of anthocyanin- and proanthocyanidin-rich extracts in cellular models of Parkinson's disease. Brain Res 2014; 1555: 60-77

31 Sudati JH, Vieira FA, Pavin SS, Dias GR, Seeger RL, Golombieski R, Athayde $M L$, Soares FA, Rocha JB, Barbosa NV. Valeriana officinalis attenuates the rotenone-induced toxicity in Drosophila melanogaster. Neurotoxicology 2013; 37: 118-126

32 Jansen RL, Brogan B, Whitworth AJ, Okello EJ. Effects of five Ayurvedic herbs on locomotor behaviour in a Drosophila melanogaster Parkinson's disease model. Phytother Res 2014; 28: 1789-1795

33 Kanazawa K, Sakakibara H. High content of dopamine, a strong antioxidant, in cavendish banana. J Agric Food Chem 2000; 48: 844-848

34 Pereira A, Maraschin M. Banana (Musa spp) from peel to pulp: ethnopharmacology, source of bioactive compounds and its relevance for human health. J Ethnopharmacol 2015; 160: 149-163

35 De Rus Jacquet A, Subedi R, Ghimire SK, Rochet JC. Nepalese traditional medicine and symptoms related to Parkinson's disease and other disorders: Patterns of the usage of plant resources along the Himalayan altitudinal range. J Ethnopharmacol 2014; 153: 178-189

36 Caruana M, Vassallo N. Tea polyphenols in Parkinson's disease. Adv Exp Med Biol 2015; 863: 117-137

37 Follmer $C$. Monoamine oxidase and $\alpha$-synuclein as targets in Parkinson's disease therapy. Expert Rev Neurother 2014; 14: 703-716

38 Siddique YH, Jyoti S, Naz F. Effect of epicatechin gallate dietary supplementation on transgenic Drosophila model of Parkinson's disease. J Diet Suppl 2014; 11: 121-130

39 Li XZ, Zhang SN, Wang KX, Liu HY, Yang ZM, Liu SM, Lu F. Neuroprotective effects of extract of Acanthopanax senticosus harms on SH-SY5Y cells overexpressing wild-type or A53T mutant $\alpha$-synuclein. Phytomedicine 2014; 21: 704-711

40 Beppe GJ, Dongmo AB, Foyet HS, Tsabang N, Olteanu Z, Cioanca O, Hancianu M, Dimo T, Hritcu L. Memory-enhancing activities of the aqueous extract of Albizia adianthifolia leaves in the 6-hydroxydopamine-lesion rodent model of Parkinson's disease. BMC Complement Altern Med 2014; 14: 142

41 Berrocal R, Vasudevaraju P, Indi SS, Sambasiva Rao KR, Rao KS. In vitro evidence that an aqueous extract of Centella asiatica modulates $\alpha$ synuclein aggregation dynamics. J Alzheimers Dis 2014; 39: 457-465

42 Li H, Park G, Bae N, Kim J, Oh MS, Yang HO. Anti-apoptotic effect of modified Chunsimyeolda-tang, a traditional Korean herbal formula, on MPTP-induced neuronal cell death in a Parkinson's disease mouse model. J Ethnopharmacol 2015; 176: 336-344

43 Bae N, Chung S, Kim HJ, Cha JW, Oh H, Gu MY, Oh MS, Yang HO. Neuroprotective effect of modified Chungsimyeolda-tang, a traditional Korean herbal formula, via autophagy induction in models of Parkinson's disease. J Ethnopharmacol 2015; 159: 93-101

44 Purushothuman S, Nandasena C, Peoples CL, El Massri N, Johnstone DM, Mitrofanis J, Stone J. Saffron pre-treatment offers neuroprotection to nigral and retinal dopaminergic cells of MPTP-Treated mice. J Parkinsons Dis 2013; 3: 77-83

45 Jahromi SR, Haddadi M, Shivanandappa T, Ramesh SR. Modulatory effect of Decalepis hamiltonii on ethanol-induced toxicity in transgenic Drosophila model of Parkinson's disease. Neurochem Int 2015; 80: 1-6

46 Guo H, Shi F, Li M, Liu Q Yu B, Hu L. Neuroprotective effects of Eucommia ulmoides Oliv. and its bioactive constituent work via ameliorating the ubiquitin-proteasome system. BMC Complement Altern Med 2015; 15: 151

47 Kwon SH, Ma SX, Hong SI, Kim SY, Lee SY, Jang CG. Eucommia ulmoides Oliv. bark attenuates 6-hydroxydopamine-induced neuronal cell death through inhibition of oxidative stress in SH-SY5Y cells. J Ethnopharmacol 2014; 152: 173-182

48 Doo AR, Kim SN, Hahm DH, Yoo HH, ParkJY, Lee H, Jeon S, Kim J, Park SU, Park HJ. Gastrodia elata Blume alleviates L-DOPA-induced dyskinesia by normalizing FosB and ERK activation in a 6-OHDA-lesioned Parkinson's disease mouse model. BMC Complement Altern Med 2014; 14: 107

49 Im AR, Kim YH, Uddin MR, Chae S, Lee HW, Kim YS, Lee MY. Neuroprotective effects of Lycium chinense Miller against rotenone-induced neurotoxicity in PC12 cells. Am J Chin Med 2013; 41: 1343-1359

50 Siddique YH, Faisal M, Naz F, Jyoti S, Rahul. Role of Ocimum sanctum leaf extract on dietary supplementation in the transgenic Drosophila model of Parkinson's disease. Chin J Nat Med 2014; 12: 777-781
51 Khurana N, Gajbhiye A. Ameliorative effect of Sida cordifolia in rotenone induced oxidative stress model of Parkinson's disease. Neurotoxicology 2013; 39: 57-64

52 Gokul K, Muralidhara. Oral supplements of aqueous extract of tomato seeds alleviate motor abnormality, oxidative impairments and neurotoxicity induced by rotenone in mice: relevance to Parkinson's disease. Neurochem Res 2014; 39: 1382-1394

53 Kosaraju J, Chinni S, Roy PD, Kannan E, Antony AS, Kumar MN. Neuroprotective effect of Tinospora cordifolia ethanol extract on 6-hydroxy dopamine induced Parkinsonism. Indian J Pharmacol 2014; 46: 176180

54 Prakash J, Chouhan S, Yadav SK, Westfall S, Rai SN, Singh SP. Withania somnifera alleviates parkinsonian phenotypes by inhibiting apoptotic pathways in dopaminergic neurons. Neurochem Res 2014; 39: 2527-2536

55 Nathan J, Panjwani S, Mohan V, Joshi V, Thakurdesai PA. Efficacy and safety of standardized extract of Trigonella foenum-graecum L. seeds as an adjuvant to L-Dopa in the management of patients with Parkinson's disease. Phytother Res 2014; 28: 172-178

56 Ryu HW, Oh WK, Jang IS, Park J. Amurensin G induces autophagy and attenuates cellular toxicities in a rotenone model of Parkinson's disease. Biochem Biophys Res Commun 2013; 433: 121-126

57 Fujimaki T, Saiki S, Tashiro E, Yamada D, Kitagawa M, Hattori $N$ Imoto $M$. Identification of licopyranocoumarin and glycyrurol from herbal medicines as neuroprotective compounds for Parkinson's disease. PLoS One 2014; 9: e100395

58 Budzianowski J. Tytoń - raz w zakładzie leczniczym. Czy zawiera substancje o właściwościach leczniczych? [Tobacco - once a medicinal plant. Does it contain substances with medicinal properties?]. Przegl Lek 2013; 70: 865-868

59 Barreto GE, Iarkov A, Moran VE. Beneficial effects of nicotine, cotinine and its metabolites as potential agents for Parkinson's disease. Front Aging Neurosci 2015; 6: 340

60 Sun A, Xu X, Lin J, Cui X, Xu R. Neuroprotection by saponins. Phytother Res 2015; 29: 187-200

61 Ahmed T, Gilani AU, Abdollahi M, Daglia M, Nabavi SF, Nabavi SM. Berberine and neurodegeneration: A review of literature. Pharmacol Rep 2015; 67: 970-979

62 Wu CR, Tsai CW, Chang SW, Lin CY, Huang LC, Tsai CW. Carnosic acid protects against 6-hydroxydopamine-induced neurotoxicity in in vivo and in vitro model of Parkinson's disease: involvement of antioxidative enzymes induction. Chem Biol Interact 2015; 225: 40-46

63 Zhang Z, Li G, Szeto SS, Chong CM, Quan Q Huang C, Cui W, Guo B, Wang Y, Han Y, Michael Siu KW, Yuen Lee SM, Chu IK. Examining the neuroprotective effects of protocatechuic acid and chrysin on in vitro and in vivo models of Parkinson disease. Free Radic Biol Med 2015; 84: $331-343$

64 Siddique YH, Jyoti S, Naz F. Effect of epicatechin gallate dietary supplementation on transgenic Drosophila model of Parkinson's disease. J Diet Suppl 2014; 11: 121-130

65 Tavassoly 0, Kakish J, Nokhrin S, Dmitriev O, Lee JS. The use of nanopore analysis for discovering drugs which bind to $\alpha$-synuclein for treatment of Parkinson's disease. Eur J Med Chem 2014; 88: 42-54

66 Antunes MS, Goes AT, Boeira SP, Prigol M, Jesse CR. Protective effect of hesperidin in a model of Parkinson's disease induced by 6-hydroxydopamine in aged mice. Nutrition 2014; 30: 1415-1422

67 Wu AG, Wong VK, Xu SW, Chan WK, Ng CI, Liu L, Law BY. Onjisaponin B derived from Radix Polygalae enhances autophagy and accelerates the degradation of mutant $\alpha$-synuclein and huntingtin in PC-12 cells. Int J Mol Sci 2013; 14: 22618-22641

68 Fredholm BB, Battig K, Holmén J, Nehlig A, Zvartau EE. Actions of caffeine in the brain with special reference to factors that contribute to its widespread use. Pharmacol Rev 1999; 51: 83-133

69 Ludwig IA, Clifford MN, Lean ME, Ashihara H, Crozier A. Coffee: biochemistry and potential impact on health. Food Funct 2014; 5: 1695-1717

70 Qi H, Li S. Dose-response meta-analysis on coffee, tea and caffeine consumption with risk of Parkinson's disease. Geriatr Gerontol Int 2014; 14: $430-439$

71 Gatto EM, Melcon C, Parisi VL, Bartoloni L, Gonzalez CD. Inverse association between yerba mate consumption and idiopathic Parkinson's disease. A case-control study. J Neurol Sci 2015; 356: 163-167

72 Pohanka $M$. The perspective of caffeine and caffeine derived compounds in therapy. Bratisl Med J 2015; 116: 520-530 
73 Ribeiro JA, Sebastião AM, de Mendonça A. Adenosine receptors in the nervous system: pathophysiological implications. Prog Neurobiol 2002; 68: 377-392

74 Ribeiro JA, Sebastião AM, de Mendonça A. Participation of adenosine receptors in neuroprotection. Drug News Perspect 2003; 16: 80-86

75 Fredholm BB, IJzerman AP, Jacobson KA, Linden J, Müller CE. International Union of Basic and Clinical Pharmacology. LXXXI. Nomenclature and classification of adenosine receptors - an update. Pharmacol Rev 2011; 63: $1-34$

76 Boison D. Adenosine as a neuromodulator in neurological diseases. Curr Opin Pharmacol 2008; 8: 2-7

77 Pinna A, Wardas J, Simola N, Morelli M. New therapies for the treatment of Parkinson's disease: adenosine $A_{2 A}$ receptor antagonists. Life Sci 2005; 77: 3259-3267

78 Sääksjärvi K, Knekt P, Rissanen H, Laaksonen MA, Reunanen A, MännistöS. Prospective study of coffee consumption and risk of Parkinson's disease. Eur J Clin Nutr 2008; 62: 908-915

79 Ascherio A, Zhang SM, Hernán MA, Kawachi I, Colditz GA, Speizer FE, Willett WC. Prospective study of caffeine consumption and risk of Parkinson's disease in men and women. Ann Neurol 2001; 50: 56-63

80 Chen JF, Chern Y. Impacts of methylxanthines and adenosine receptors on neurodegeneration: human and experimental studies. Handb Exp Pharmacol 2011: 200: 267-310

81 Seidl SE, Potashkin JA. The promise of neuroprotective agents in Parkinson's disease. Front Neurol 2011; 2: 68

82 Chen JF, Xu K, Petzer JP, Staal R, Xu YH, Beilstein M, Sonsalla PK, Castagnoli K, Castagnoli N Jr. N, Schwarzschild MA. Neuroprotection by caffeine and $\mathrm{A}_{2 \mathrm{~A}}$ adenosine receptor inactivation in a model of Parkinson's disease. J Neurosci 2001; 21: RC143

$83 \mathrm{Xu} \mathrm{K,} \mathrm{Xu} \mathrm{YH,} \mathrm{Chen} \mathrm{JF,} \mathrm{Schwarzschild} \mathrm{MA.} \mathrm{Caffeine's} \mathrm{neuroprotection}$ against 1-methyl-4-phenyl-1,2,3,6-tetrahydropyridine toxicity shows no tolerance to chronic caffeine administration in mice. Neurosci Lett 2002; 322: 13-16
84 Kalda A, Yu L, Oztas E, Chen JF. Novel neuroprotection by caffeine and adenosine $A_{2 A}$ receptor antagonists in animal models of Parkinson's disease. J Neurol Sci 2006; 248: 9-15

85 Morelli $M$, Wardas J. Adenosine $\mathrm{A}_{2 \mathrm{a}}$ receptor antagonists: potential therapeutic and neuroprotective effects in Parkinson's disease. Neurotox Res 2008; 3: 545-556

$86 \mathrm{Xu} K, X u Y H$, Chen JF, Schwarzschild MA. Neuroprotection by caffeine: time course and role of its metabolites in the MPTP model of Parkinson's disease. Neuroscience 2010; 167: 475-481

87 Postuma RB, Lang AE, Munhoz RP, Charland K, Pelletier A, Moscovich M, Filla L, Zanatta D, Rios Romenets S, Altman R, Chuang R, Shah B. Caffeine for treatment of Parkinson disease. A randomized controlled trial. Neurology 2012; 79: 651-658

88 ClinicalTrials.gov. Caffeine for motor manifestations of Parkinson's disease. Available at https://www.clinicaltrials.gov/ct2/show/study/ NCT01190735. Accessed January 21, 2016

89 ClinicalTrials.gov. Caffeine as a therapy for Parkinson's disease. Available at https://www.clinicaltrials.gov/ct2/show/NCT01738178. Accessed January 21, 2016

90 Petzer JP, Castagnoli N, Schwarzschild MA, Chen JF, Van der Schyf CJ. Dual-target-directed drugs that block monoamine oxidase B and adenosine $A_{2 A}$ receptors for Parkinson's disease. Neurotherapeutics 2009; 6: $141-151$

91 Petzer JP, Petzer A. Caffeine as a lead compound for the design of therapeutic agents for the treatment of Parkinson's disease. Curr Med Chem 2015; 22: 975-988

92 Shoulson I, Chase T. Caffeine and the antiparkinsonian response to levodopa or piribedil. Neurology 1975; 25: 722-724

93 Kartzinel R, Shoulson I, Calne DB. Studies with bromocriptine: III. Concomitant administration of caffeine to patients with idiopathic parkinsonism. Neurology 1976; 26: 741-743 